\title{
SPECIES DIFFERENCES IN SENSITIVITY OF T LYMPHOCYTES TO IMMUNOSUPPRESSIVE EFFECTS OF FK 5061
}

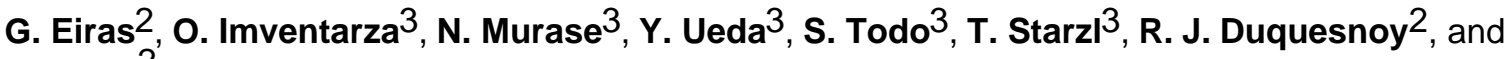 \\ A. Zeevi $^{2}$ \\ ${ }^{2}$ The Department of Pathology, University of Pittsburgh Medical School, Pittsburgh, Pennsylvania \\ 15213 \\ ${ }^{3}$ The Department of Surgery, University of Pittsburgh Medical School, Pittsburgh, Pennsylvania \\ 15213
}

FK 506 is a novel immunosuppressive drug isolated from Streptomyces tsukubaensis in 1984 (1). Initial in vitro studies have indicated that FK 506 is a potent inhibitor of murine and human mixed lymphocyte reactions and can prevent the generation of cytolytic cells. FK 506 suppresses T cell-dependent responses and this effect appears to be mediated through the inhibition of interleukin- 2 release and diminished expression of the IL-2 receptor on activated T cells $(2,3)$. The strong immunosuppressive effect of FK 506 has been observed during primary activation of lymphocytes, such as the mixed leukocyte reaction and the secondary proliferation of alloreactive $\mathrm{T}$ lymphocytes generated from MLR or propagated from organ transplant biopsies as measured by the primed lymphocyte test (4).

Although both FK 506 and cyclosporine exhibit similar mechanisms of action, the immunosuppressive effect of FK 506 is several-hundred-fold greater than that of CsA. Synergism between the two drugs has been observed in vivo and in vitro, as demonstrated by significant immunosuppressive effects of combinations of drugs at low doses that are individually ineffective $(5,6)$. Synergism has also been noted between FK 506 and azathioprine (7).

In vivo studies have also established the effectiveness of FK 506 in several allograft models. Todo et al. showed that FK 506 greatly prolongs allograft survival of heterotopic heart transplants in rats (8-10), and renal and liver transplants in dogs (11). In these experiments, FK 506 was found to be effective at dose levels of $1-1.5 \mathrm{mg} / \mathrm{kg} /$ day - however, preliminary studies with kidney transplants performed in baboons indicated that this dose of FK 506 was ineffective in prolonging graft survival (12). In vitro studies were conducted to quantitate the immunosuppressive effects of FK 506 on the MLR with lymphocytes from baboons, dogs, rats, and humans.

Heparinized blood was collected from normal dogs $(n=9)$, rats $(n=3)$, baboons $(n=10)$ and humans $(\mathrm{n}=8)$. Mononuclear cells were isolated by Ficoll-Hypaque sedimentation and unidirectional MLR cultures were set up in triplicate with equal numbers $\left(10^{6} / \mathrm{ml}\right)$ of responders and irradiated stimulators in $10 \%$ autologous serum and incubated for 6 days at $37^{\circ} \mathrm{C}$ and $5 \%$ $\mathrm{CO}_{2}$. During the final $20 \mathrm{hr}$ of incubation, each culture was labeled with $1 \mu \mathrm{Ci}$ of [3H]thymidine (ICN Radiochemicals, $1 \mathrm{mCi} / \mathrm{ml}$ ), harvested, and counted in a liquid scintillation counter. The dose effect of FK 506 and CsA on MLR activity was measured at different concentrations of the drug ranging from $0.03-10 \mathrm{ng} / \mathrm{ml}$ for FK 506 to $3.5-2500 \mathrm{ng} / \mathrm{ml}$ for CsA.

\footnotetext{
${ }^{1}$ This work was supported by Grants AI-23467 and HL-36416 from the National Institutes of Health.
} 
For each culture the ID50 dose was calculated as the concentration of FK 506 or CsA that caused a $50 \%$ inhibition of the MLR.

Figure 1 illustrates, that the ID50 of FK 506 was about 10-fold higher for baboon lymphocytes $(3.85 \pm 2 \mathrm{ng} / \mathrm{ml}$ ) than for lymphocytes from the other three species (rats $0.33 \pm 0.2 \mathrm{ng} / \mathrm{ml}$; humans $0.29 \pm 0.2 \mathrm{ng} / \mathrm{ml}$; dogs $0.59 \pm 0.58 \mathrm{ng} / \mathrm{ml}$ ). These differences in FK 506 sensitivity were statistically significant $(P<0.001)$. Similar differences between ID50 values were observed for CsA, although their magnitudes were somewhat lower (Fig. 2). The ID50 of CsA was Significantly higher for baboons $(212 \pm 161 \mathrm{ng} / \mathrm{ml})$ than for rats $(45 \pm 4 \mathrm{ng} / \mathrm{ml})$; humans $(50.5$ $\pm 28.5 \mathrm{ng} / \mathrm{ml})$ and dogs $(40.8 \pm 18.5 \mathrm{ng} / \mathrm{ml})$. These data also extend previous observations that FK 506 is 100-300 times more potent in inhibiting MLR than CsA (4).

Comparable differences in FK506 sensitivity were observed in vivo in different allograft models. Table 1 summarizes the survival rates of kidney transplants in baboons versus kidney transplants in dogs and cardiac transplants in rats. In the baboon and dog models FK 506 was administered orally, in the rat model the drug was administered intramuscularly. Successful prolongation of RT-I-incompatible cardiac allograft in rats was achieved at FK506 doses of $1.28 \mathrm{mg} / \mathrm{kg} /$ day with a mean survival of 99 days (10), whereas untreated allografts only survived 6 days. At daily doses of $1.5 \mathrm{mg} / \mathrm{kg} / \mathrm{day}$, FK 506 prolonged allogeneic renal transplants from mongrel to beagle dogs from 14 days to 61 days (11). However, a similar dose of FK 506 ( $2 \mathrm{mg} / \mathrm{kg} /$ day $)$ induced a modest and insignificant prolongation of renal transplant survival in baboons (16 days versus 9 days for untreated controls). Considerably higher doses of FK 506 (12 and $18 \mathrm{mg} / \mathrm{kg} /$ day) were necessary for baboons to achieve allograft survivals comparable to those observed in rats and dogs at lower doses (Table 1).

The results of these in vivo and in vitro studies demonstrate species differences in sensitivity in the immunosuppressive effects of FK 506. The baboon model requires almost tenfold higher doses of FK 506 than the rat and dog models to achieve optimal immunosuppression. The in vitro assays indicate that FK 506 sensitivity of human lymphocytes is more similar to that for dogs and rats rather than baboons. These findings suggest that FK 506 at doses of $1.5 \mathrm{mg} / \mathrm{kg} /$ day might provide effective immunosuppression of human allografts. However only clinical trials can establish the optimal administration of this drug.

In transplant patients the optimization of immunosuppressive treatment depends on the administration of appropriate doses that have minimal side effects and the monitoring of drug levels. Pharmacokinetic and pharmacodynamic evaluations have aided in developing individualized immunosuppressive therapy (13). Furthermore drug sensitivity of in vitro lymphocyte activation seems useful, and considerable variations have been seen between different individuals (14). In this study species differences in FK 506 sensitivity of MLR reflect the efficacy of FK 506 treatment in prolonging allograft survival. Thus in vitro studies of drug sensitivity of lymphocyte activation are useful in determining optimal drug doses to ensure successful transplantation.

\section{REFERENCES}

1. Kino T, Inamura N, Sakai F, et al. Effect of FK 900506 on human mixed lymphocyte reaction in vitro. Transplant Proc 1987;19(5, suppl 6):36. [PubMed: 2445071]

2. Kino T, Hatanaka H, Miyata S, et al. FK 506, a novel immunosuppressant isolated from Streptomyces. J Antibiot 1987;40:1256. [PubMed: 2445722]

3. Kino T, Hatanaka H, Hashimoto M, et al. Immunosuppressive effects of FK 506 in vitro. J Antibiot 1987;40:1249. [PubMed: 2445721]

4. Zeevi A, Duquesnoy R, Eiras G, et al. In vitro immunosuppressive effects of FR 900506 on human T lymphocyte alloactivation. Surg Res Commun 1987;1:315. 
5. Sanghvi A, Warty V, Zeevi A, et al. FK506 enhances cyclosporine uptake by peripheral blood lymphocytes. Transplant Proc 1987;19(5, suppl 6):45. [PubMed: 2445074]

6. Zeevi A, Duquesnoy R, Eiras G, et al. Immunosuppressive effect of FK on in vitro lymphocyte activation: synergism with CsA. Transplant Proc 1987;19(5, suppl 6):40. [PubMed: 2445073]

7. Zeevi A, Duquesnoy R, Eiras G, et al. In vitro immunosuppressive effects of FK 506 in combinations with other drugs. Transplant Proc 1988;20(1, suppl 1):220.

8. Ochiai T, Nakajima K, Nagata M, et al. Studies of the induction and maintenance of long term graft acceptance by treatment with FK 506 in heterotopic cardiac allotransplantation in rats. Transplantation 1987;44:734. [PubMed: 2447689]

9. Inamura N, Nakahara K, Kino T, et al. Prolongation of skin allograft survival in rats by a novel immunosuppressive agent, FK 506. Transplantation 1988;45:206. [PubMed: 2447690]

10. Murase N, Todo S, Lee PH, et al. Heterotropic heart transplantation in the rat receiving FK506 alone or with CsA. Transplant Proc 1987;19:71. [PubMed: 2445081]

11. Todo S, Demetris J, Ueda Y, et al. Canine kidney transplantation with FK 506 alone or in combination with cyclosporine and steroids. Transplant Proc 1987;19:57. [PubMed: 2445076]

12. Todo S, Ueda Y, Demetris AJ, et al. Immunosuppression of canine, monkey, and baboon allografts by FK 506 with special synergism with other drugs, and to tolerance induction. Surgery 1988;104:239. [PubMed: 2456627]

13. Kahan B. Individualization of cyclosporine therapeutic drug pharmacokinetic and pharmacodynamic parameters. Transplantation 1985;40:457. [PubMed: 3904087]

14. Sander B, Brigati E, Moller E. Inhibition of in vitro alloreactivity by cyclosporine A: evidence for an interindividual variation in sensitivity. Scand J Immunol 1986;23:435. [PubMed: 2939552]

Transplantation. Author manuscript; available in PMC 2010 November 5. 


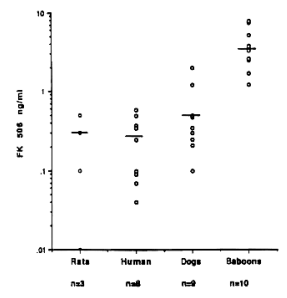

FIGURE 1.

ID50 values for FK 506 in MLR cultures from rats, human, dogs, and baboons. Each point represents one experiment done in triplicate. Statistical analysis of the ID50 values was done using the unpaired Student's $t$ test. The analysis was done for baboons vs. dogs and baboons vs. humans. 


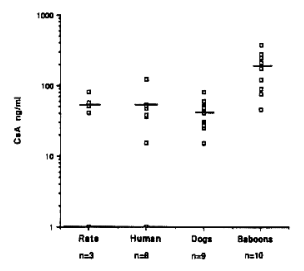

FIGURE 2.

ID50 values for CsA in MLR cultures from rats, humans, dogs, and baboons. Each point represents one experiment done in triplicate. 


\section{TABLE 1}

Effect of FK 506 on allograft survival in the three animal species

\begin{tabular}{lll}
\hline $\begin{array}{l}\text { Species } \boldsymbol{a} \\
(\mathbf{n})\end{array}$ & $\begin{array}{l}\text { FK treatment } \\
(\mathbf{m g} / \mathbf{k g} / \text { day })\end{array}$ & $\begin{array}{l}\text { Survival } \\
\text { (days) }\end{array}$ \\
\hline Rats (6) & 1.28 & $99 \pm 51$ \\
Canine (6) & 1.5 & $61 \pm 33$ \\
Baboons (2) & 2 & $16 \pm 3$ \\
Baboons (6) & 12 & $67 \pm 26$ \\
Baboons (6) & 18 & $90 \pm 44$ \\
\hline
\end{tabular}

${ }^{a}$ Cardiac transplant in rats, renal transplant in canines and baboons. 